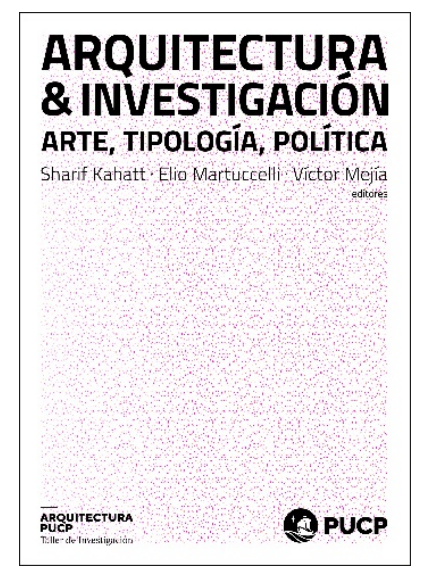

Arquitectura \& Investigación

Arte, tipología, política

ISBN 978-612-47555-5-2

Arte y ciudad desde la institucionalidad. Tres intervenciones recientes en el espacio público de Lima

Alvaro Josué Sánchez Casas

Para citar este artículo: Sánchez C., A. (2021). Arte y ciudad desde la institucionalidad. Tres intervenciones recientes en el espacio público de Lima. En S. Kahatt, E. Martuccelli y V. Mejía (Eds.), Arquitectura \& Investigación. Arte, tipología, política (p. 37.52). Pontificia Universidad Católica del Perú.

DOI: $\underline{10.18800 / 978-612-47555-5-2.002}$

Para acceder a este artículo: https://doi.org/10.18800/978-612-47555-5-2.002

\title{
ARQUITECTURA PUCP
}


00

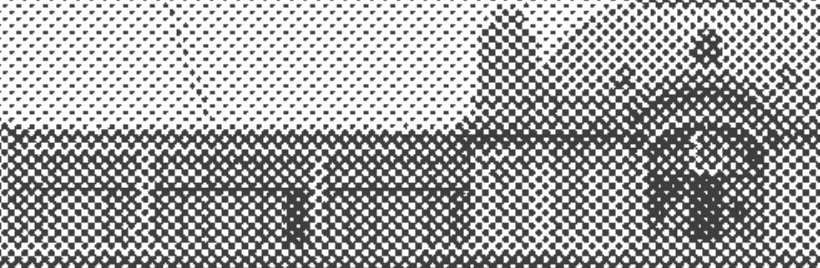

os 0.

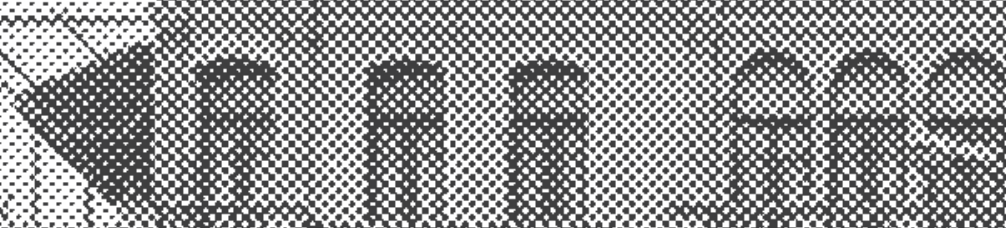
mon
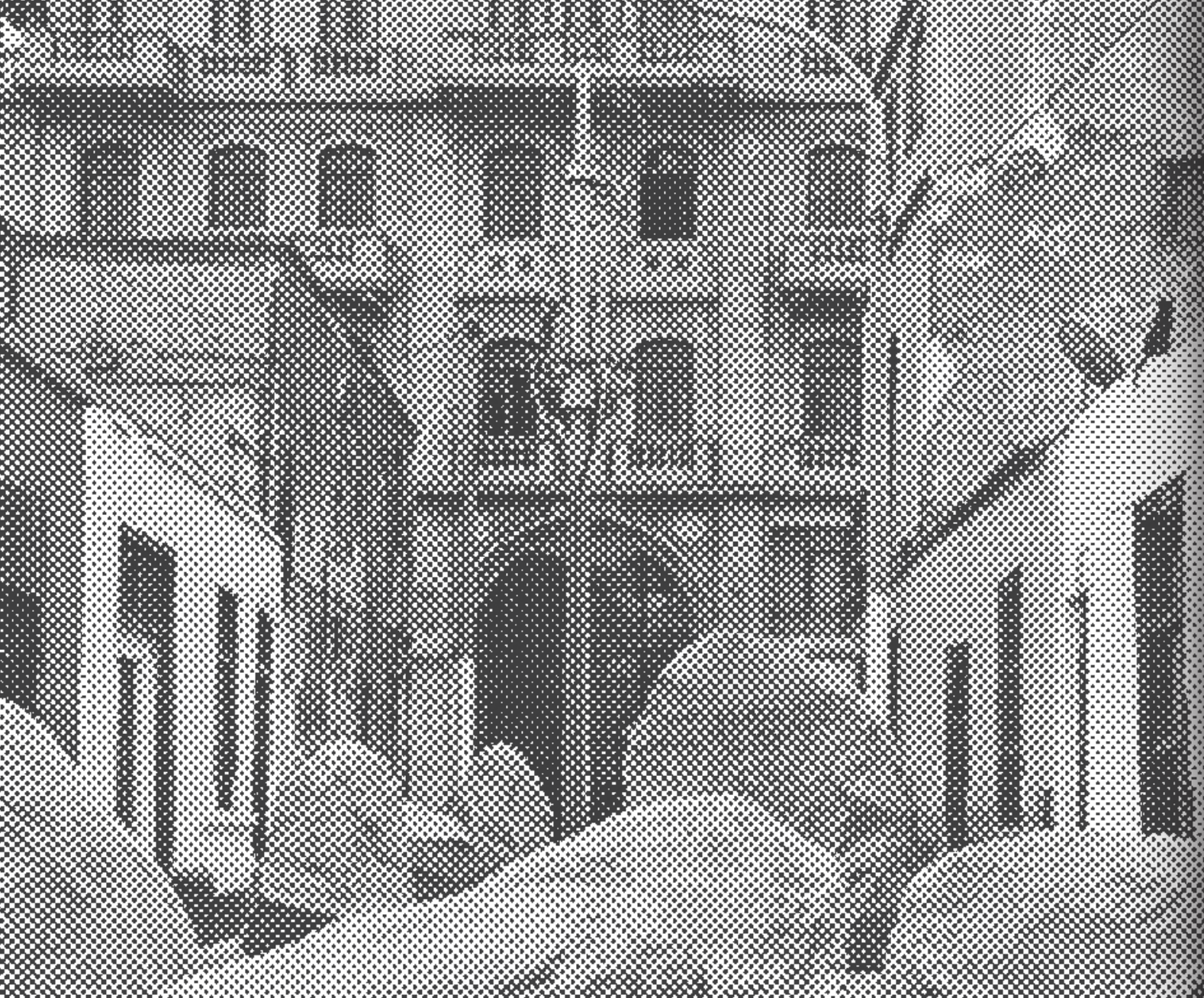

然然

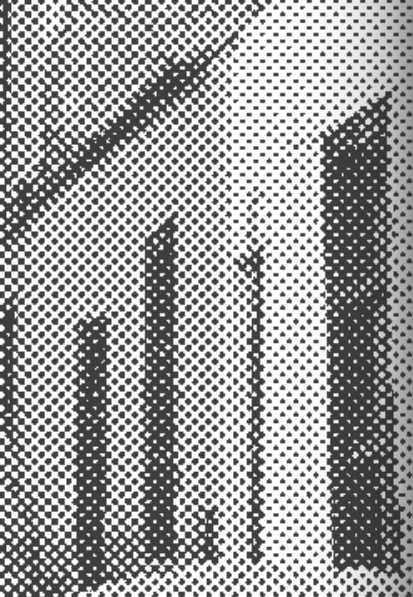




\title{
ARTE Y CIUDAD DESDE LA INSTITUCIONALIDAD Tres intervenciones recientes en el espacio público de Lima
}

\author{
Alvaro Josué Sánchez Casas
}

\begin{abstract}
Resumen
El presente artículo se enmarca en la problemática del arte y el espacio público al interior de la nueva configuración urbana de Lima contemporánea. Desde fines del siglo XX, Lima enfrenta una crisis del espacio público, el cual ha perdido su carácter como lugar de encuentro, interacción e integración de sus habitantes, así como de espacio común, referencial y simbólico de la condición de ciudadano. Frente a esto, el arte juega hoy un rol fundamental de transformación de la ciudad. En la actualidad existen varios proyectos que, desde distintas visiones, están interviniendo artísticamente diversos espacios públicos de Lima. El artículo examina tres de estos espacios intervenidos desde la institucionalidad con visiones disímiles, para analizar sus alcances y resultados.
\end{abstract}

Palabras clave: arte, espacio público, espacio urbano, ciudad, Lima.

\section{Abstract}

This article is written through the lens of the complex coexistence between art and public space in the new scene of contemporary Lima's urban condition. Since the end of the 20th century, Lima has been enduring the crises of public space. It has lost its role and quality as a meeting place for interaction and integration, as well as a referential and symbolic space for its citizens. In this context, art today plays a fundamental role in the transformation of the city. Currently, there are several projects that, drawn from different perspectives, are shaping various public spaces in Lima through art. The following article examines three of these public spaces, envisioned by different institutional mindsets with divergent ideas about the city, in order to analyze their scopes and results.

Alvaro Josué Sánchez Casas Estudiante de la Facultad de Arquitectura y Urbanismo PUCP. Realizó prácticas en el Museo de Arte de Lima y una estancia de un año en la Accademia di Archittetura di Mendrisio de la Universitá della Svizzera Italiana.
Keywords: art, public space, urban space, city, Lima. 


\title{
ARTE Y CIUDAD DESDE LA INSTITUCIONALIDAD \\ Tres intervenciones recientes en el espacio público de Lima
}

\author{
Alvaro Josué Sánchez Casas
}

\section{Arte, espacio público y ciudad: Lima contemporánea}

Históricamente, «el espacio público en sus diversas interpretaciones, definiciones y formas construidas fue llamado a ser el escenario de encuentro entre el arte y la gente» (Mitrache 2012: 562). ${ }^{1}$ El arte enriquece la vida del hombre de múltiples maneras. En el ámbito del espacio público, en las ciudades contemporáneas su papel es altamente significativo. «Las personas en una ciudad moderna son como ratas en un laberinto. Necesitan una herramienta de reconocimiento espacial para conocer el entorno en el que han sido forzados a vivir», ${ }^{2}$ dice Anna Januchta-Szostak (2010: 75). El arte puede ser esa herramienta.

En las caóticas y alienadas ciudades contemporáneas, el arte tiene la capacidad de servir de herramienta de identificación del espacio físico urbano y, a partir de allí, de mejorar la percepción de su calidad y atractivo cultural y social. Así, puede llevar de la identificación de un espacio por un individuo a la identificación del individuo con dicho espacio, constituido en un «lugar» con sentido (Januchta-Szostak 2010: 78). Para el ciudadano, ello equivale a adquirir un sentido de pertenencia e identidad con esta, así como la posibilidad de interactuar con los otros habitantes y ejercer ciudadanía.

El sentido y el lugar del arte en la concepción del espacio público es un asunto de importancia fundamental, que puede ser crucial en realidades como la de Lima. En ella, desde fines del siglo XX, la situación del arte y el espacio público es crítica. El parque, la plaza y la calle han visto disminuido aquel carácter definido por la libre circulación, la interacción y la integración de los ciudadanos; han sido privatizados, la ordenación territorial ha seguido los dictados de la economía de mercado y la ciudad ha crecido desmesuradamente en perjuicio de los espacios verdes y el tejido urbano. Como señala Juan Tokeshi, «el momento actual de la ciudad es de fricción y transformación» y Lima puede ser caracterizada como un «contenedor difuso», donde el valor del espacio público físico y el concepto de comunidad se han diluido (2013: 119).

La falta de compromiso de las personas con el entorno urbano y la ausencia de comunicación entre los vecinos y los gobiernos locales han 
coadyuvado a la precariedad de los espacios públicos y a la fragmentación y dispersión de la ciudad, ello en el marco de una sociedad caracterizada por la informalidad, el individualismo, el consumismo y una frágil institucionalidad. Reflejo de esta situación, el arte público ha seguido un camino similar y se ha devaluado en calidad, autenticidad y belleza. Urbanistas como Wiley Ludeña no dudan en expresar su decepción y describir el arte público actual como un heterogéneo conjunto de esculturas huachafas, kitsch, naif o chicha, carentes de la dignidad de muchos monumentos erigidos en décadas pasadas (2013: 157).

Sin embargo, junto a esta realidad, un cambio de perspectiva en la percepción del espacio público y del papel del arte en su configuración, ocurrido en las últimas décadas, plantea la posibilidad de redefinir ambos positivamente. De un lado, el arte asume un rol transformador de la ciudad, claramente político y cívico, y surgen propuestas de intervención artística en zonas urbano-marginales. De otro, desde una visión pragmática y comercial, se consolidan proyectos turísticos o inmobiliarios a través de la renovación y mejoramiento de los espacios públicos. En tanto, en zonas en desuso, periféricas, en los bordes de la ciudad, surgen espacios de convivencia colectiva que les otorgan el carácter de públicos, y en el seno de diversos colectivos germinan propuestas solidarias de intervención artística destinadas a mejorar las condiciones de vida y los vínculos comunitarios en las zonas de pobreza.

Así, el significado del arte en el espacio público en Lima adquiere hoy una dimensión distinta a la pasada, deja de ser un tema de ornato y se convierte en una oportunidad de cambio y mejora de la ciudad, de expresión de ciudadanía y democratización del arte. Una segunda oportunidad, en la perspectiva de darle a la ciudad un rostro humano a la vez que contemporáneo. En este objetivo se centra hoy la atención académica.

\section{El papel del arte público: de la teoría a la realidad}

La literatura en materia de arte y espacio público es profusa y diversa. El tema es hoy ampliamente debatido en los círculos académicos y teóricos de la arquitectura, el urbanismo, el arte y la sociología, e incluso la filosofía y la psicología. La ciudad, creada por el hombre para su desarrollo y disfrute, se ha convertido en un foco de desestabilización social (Gómez Aguilera 2004: 37); sus espacios colectivos se han degradado y diluido, y esto preocupa e interesa porque, inevitablemente, la condición social del ciudadano los reclama como una necesidad.

A nivel teórico, ha habido una evolución de los conceptos de arte y espacio público. Si tradicionalmente se hablaba de arte para referirse a un objeto estético, el punto de vista contemporáneo es que, si bien el arte tiene una base material, su valor no radica sólo en lo objetual, sino también en el concepto. Es decir, no es una cuestión de forma, sino de significantes: lo que importa es la relación entre el arte y el espectador. Así, para el filósofo y crítico de arte Boris Groys, una obra de arte es bella cuando su formulación material no oblitera la idea (2011). La estética actual radica 
en el sentido, es comunicacional y relacional. En esta dirección, el teórico francés Nicolás Bourriaud define el arte como «una actividad que consiste en producir relaciones con el mundo con la ayuda de signos, formas, gestos u objetos» (2008: 135).

Este giro conceptual tiene implicancias en la visión de los artistas de hoy y en el concepto de arte público, y se abre a expresiones artísticas diversas como las hechas alrededor del mundo por Banksy o Blu en graffiti, y Richard Serra o Christo \& Jeanne-Claude en site-specific; o las realizadas en el contexto local por Entes o Decertor en graffiti, y Elio Martuccelli o Abel Bentín en site-specific. Si anteriormente el arte público concernía a las esculturas colocadas en los espacios públicos, artistas como Suzanne Lacy, citada por Lucila Urda Peña, entienden que el nuevo género de arte público «es un arte visual que utiliza medios de comunicación tradicionales o no tradicionales para comunicar e interactuar con una amplia y diversa audiencia sobre asuntos relevantes para sus vidas» (Urda Peña 2015: 37).

El punto neurálgico aquí es la carga sociológica y política que conlleva este concepto. El artista hoy busca ir más allá de la experimentación personal y generar una interacción — con el observador - que promueva el diálogo y la discusión. El mejor lugar para hacerlo es el espacio público, allí donde tiene un espectador cautivo y puede generar una reacción activa en él (Urda Peña 2015: 29). Esta visión del arte define muchos de los estudios y análisis recientes sobre su relación con el espacio público. Se espera que el arte no sea solo un asunto de belleza y ornato, sino que comunique y dialogue con los viandantes y, en correlación con el concepto actual de espacio público, promueva su apropiación por los usuarios, contribuya a la construcción de identidad y ciudadanía y cumpla un rol transgresor y político de transformación (Tokeshi 2013: 124-127).

Usualmente, democratizar el arte y los espacios públicos no ha sido un objetivo de las instituciones gubernamentales; la escultura monumental en los espacios públicos ha servido al objetivo de legitimar la historia oficial y el financiamiento brindado por algunas entidades privadas solo ha buscado respaldar a las instituciones del poder. Hoy, sin embargo, ante la demanda de artistas, intelectuales y colectivos sociales diversos, hay intentos en ese sentido, desde distintas visiones. Algunos muy sencillos, que tratan de hacer accesible el arte al ciudadano común, a través de lo que se conoce como galerías al aire libre. Es el caso del Boulevard de la Cultura de Magdalena del Mar. De otro lado, por iniciativa privada, se han intervenido artísticamente espacios degradados con potencial de renovación urbana, como ha sucedido en el Callao, en su zona monumental, a través del proyecto Fugaz; lo que hoy se conoce como Monumental Callao. En otros casos, por la confluencia de intereses turísticos e inmobiliarios privados con una visión municipal de desarrollo basada en el crecimiento económico y la sustentabilidad, se han desarrollado proyectos integrales de embellecimiento, equipamiento y remodelación de las áreas públicas, que han tenido resultados favorables en el uso colectivo, como ha ocurrido en el caso del malecón de Miraflores. 


\section{FIGURA 1}

Plano de ubicación de las esculturas del Boulevard de la Cultura de Magdalena del Mar: 1. El pájaro; 2. Monumento de la amistad; 3 . Toro negro; 4. La puerta; 5. El bailarín; 6 Eco del agua; 7. Logos; 8. Sin título Elaboración propia sobre una imagen de Google Earth.

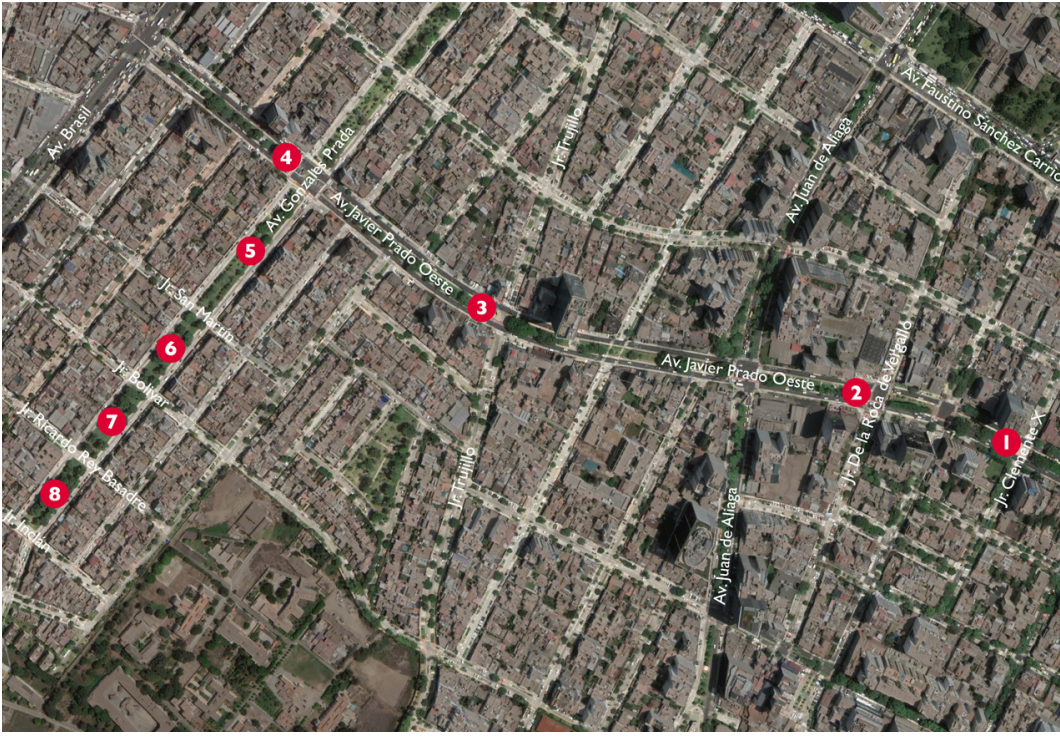

\section{El Boulevard de la Cultura de Magdalena: una galería al aire libre}

El Boulevard de la Cultura de Magdalena del Mar está situado en las avenidas Javier Prado Oeste y Parque Gonzáles Prada del distrito del mismo nombre, a lo largo de doce cuadras. Ambas avenidas tienen dos carriles en cada sentido y están flanqueadas mayormente por edificios residenciales de escasa altura, aunque, en el caso de Javier Prado Oeste, con posibilidades de ser de densidad alta (IMP 2010). La berma central de la avenida Javier Prado Oeste consiste en dos vías peatonales angostas en los extremos y un jardín central arbolado, en medio del cual se han ubicado cuatro esculturas de autores contemporáneos; ${ }^{3}$ la de la avenida Parque Gonzáles Prada consiste enteramente en un jardín arbolado y consta de otras cuatro esculturas, también de artistas contemporáneos. ${ }^{4}$

Todas las esculturas se encuentran ubicadas en el eje central de la berma. En la avenida Javier Prado, en los extremos de la cuadra cercanos al cruce vial; en la avenida Parque Gonzáles Prada, a la mitad de la cuadra. En términos de visualización, de cara al tráfico vehicular y peatonal, las esculturas de la avenida Javier Prado tienen mayor visibilidad. Espacialmente, la ubicación de las esculturas en el eje central de la berma - para guardar la simetría de la calle — responde a la antigua lógica del monumento. En la avenida Javier Prado Oeste hay una evidente voluntad de darles protagonismo como obras de arte en exhibición, pues aparecen aisladas, estableciendo una barrera tácita que solo permite la observación distante. En la avenida Parque Gonzales Prada, pese a que se ha intentado darles protagonismo colocándolas en el centro, las esculturas se pierden en el paisaje, sin lograr integrarse a él; y si bien permiten la cercanía de las personas, parecen desconectadas y solitarias. 
FIGURA 2

Escultura El Toro, de Víctor Delfín. Foto: Alvaro Sánchez.

FIGURA 3

Monumento de la Amistad, de Marcelo Wong. Foto: Alvaro Sánchez.
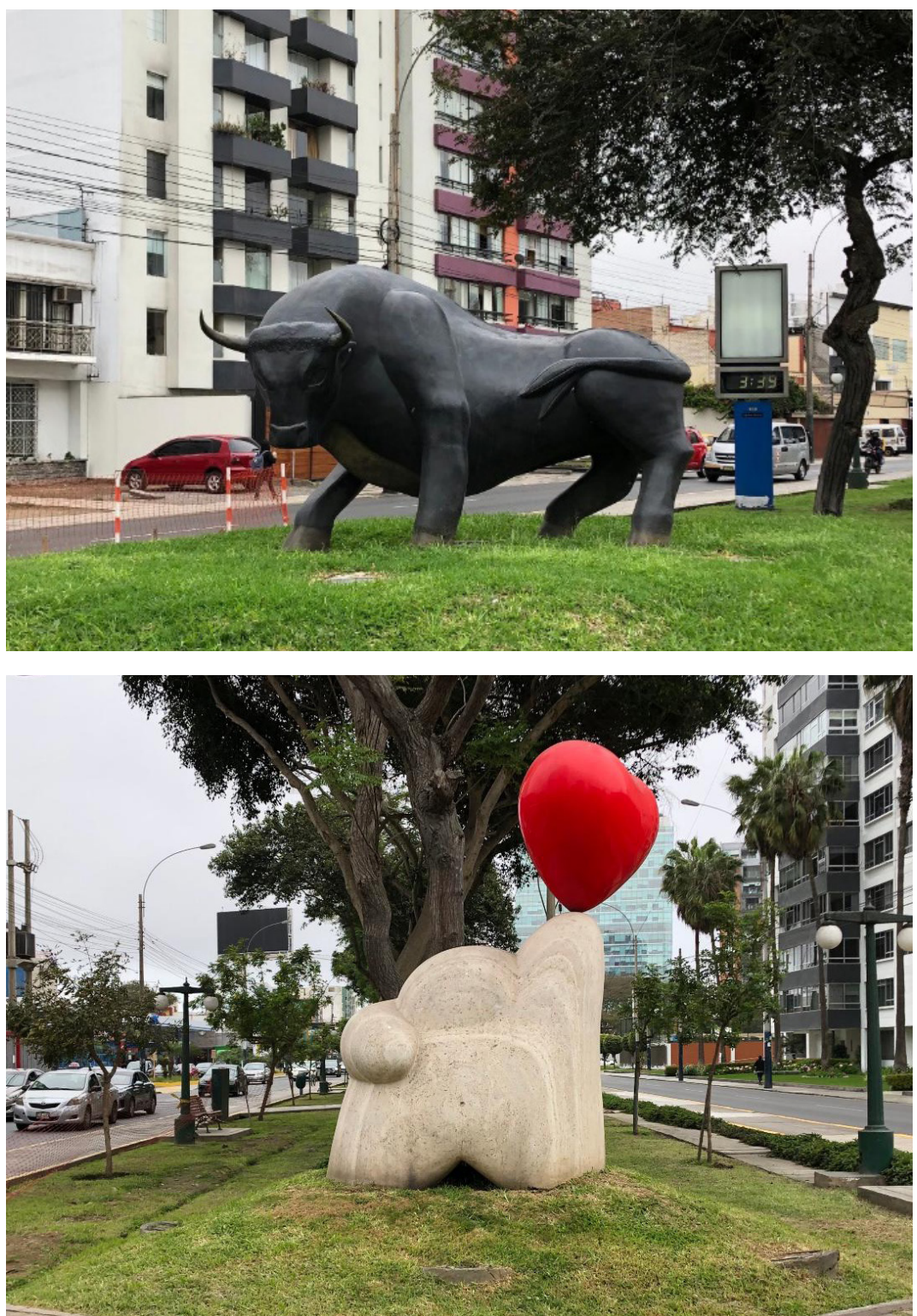
El recorrido que se plantea en la zona de la avenida Javier Prado es longitudinal y está determinado por las dos vías peatonales laterales de la berma, que trazan dos caminos definidos y un límite tácito de ingreso al jardín, no obstante lo cual muchos jóvenes —especialmente trabajadores que ofrecen servicio de delivery - utilizan los jardines como puntos de descanso y reunión. Ello, pese a que recientemente una de las vías peatonales laterales se ha habilitado como ciclovía, lo que significa un peligro para los viandantes y para los propios ciclistas, que transitan pegados a una vía vehicular de alta velocidad. En la zona del boulevard que da a la avenida Parque Gonzáles Prada, el área de la berma permanece libre y no limita el ingreso, por lo que es frecuente observar gente en los jardines, principalmente jóvenes que hacen ejercicio o pasean a sus mascotas, lo cual se ve favorecido por el entorno, ya que esta avenida está en un área netamente residencial, de menor tráfico vehicular.

Cuando se inauguró el boulevard el año 2012, el alcalde Francis Allison dijo: «a través de este eje urbano cultural, buscamos promover el arte al aire libre desde todas sus manifestaciones, rompiendo así la barrera que lo separa muchas veces del común de las gentes» (Andina 2012). El objetivo se ha cumplido en el sentido de que hay arte al alcance de todos en las calles, arte que puede ser apreciado por los transeúntes y que le otorga al barrio una imagen cultural y contemporánea. Sin embargo, siguiendo a Georgică Mitrache, en términos de arte que promueve la convivencia y la integración entre vecinos desde el espacio público, puede decirse que la entidad oficial instrumentó el arte de forma vertical para producir una imagen de élite del distrito, no participativa ni promotora de la participación, con una idea de higienización del espacio y un sentido selectivo del arte (2012). Lo positivo es que, aun así, el arte, como señala Januchta-Szostak, ha servido de punto de referencia y ha contribuido a forjar un «lugar» con sentido, con el cual se identifican los vecinos y los visitantes (2010: 78), al punto de frecuentarlo y tomarlo como un lugar de descanso y de reunión para fines privados. Como apunta Luisa Bravo, «es así como la vida social de los diferentes "públicos" produce lugares con significación comunitaria» (2013: 3), ${ }^{5}$ abiertos al intercambio y la solidaridad.

\section{Monumental Callao: regeneración urbana a partir del arte}

Monumental Callao se ubica en el Centro Histórico de la provincia constitucional del Callao, dentro de un área que comprende cuatro manzanas cuyos ejes son la calle Independencia, el jirón Constitución y el pasaje Gálvez. Es una zona de valor patrimonial e histórico, considerada intangible, intervenida desde el año 2016 por el proyecto Fugaz, el arte de convivir, una iniciativa artístico-comercial del sector privado, creada con la finalidad de recuperar esta zona de viviendas deterioradas y tugurizadas, inserta en un barrio con un elevado índice de actividad delictiva, cercano al puerto del Callao.

La intervención supuso la repavimentación de algunas cuadras del jirón Constitución y el pasaje Gálvez, el pintado de alrededor de treinta fachadas y de unos sesenta graffiti ejecutados por artistas urbanos, 


\section{FIGURA 4}

Plano de intervención de Monumental Callao.1. Casa Ronald. 2. Plaza Matriz. En rojo, área de intervención. Elaboración propia sobre una imagen de Google Earth.

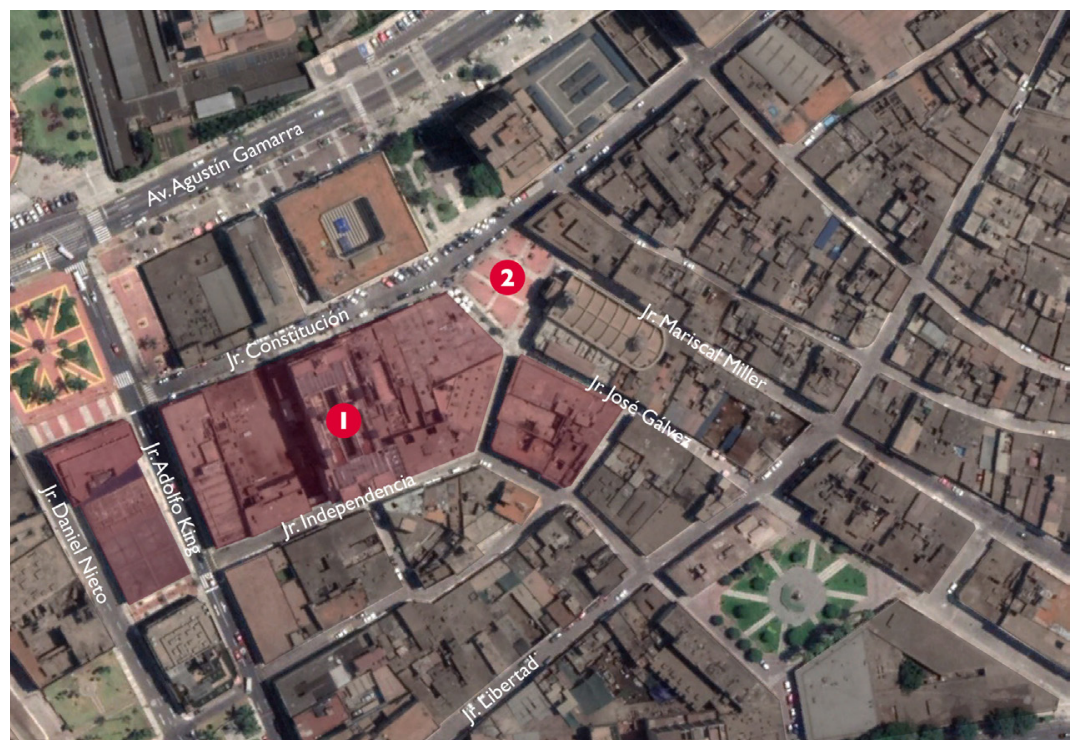

entre ellos Elliot Túpac, Decertor, Entes \& Pésimo y El Salsa, entre otros. También se intervino la Casa Ronald, un edificio de seis pisos y estilo inglés con doble frontis, de inicios del siglo XX, que conecta el jirón Constitución y la calle Independencia a la altura de la cuadra 2 de ambas vías a través de un pasaje, donde, atraídos por la imagen artística de la zona, se establecieron luego algunos atelieres, exclusivos restaurantes y tiendas, galerías de arte y comerciales. Otros artistas, como Abel Bentín y los hermanos José Luis y José Carlos Martinat, intervinieron las calles temporalmente con obras site-specifc. La revista de arte contemporáneo Artishock describió entonces la zona como un destino para el arte, constituido al estilo de Wynwood, en Miami, según afirmaban los representantes de Fugaz (Artishock 2016).

En poco tiempo, de un barrio marginal, Monumental Callao pasó a ser un barrio «trendy», «cool», de viejas calles y una atractiva oferta artística, cultural y de negocios (Echecopar s/f). Un lugar que ofrecía, además, desarrollo turístico, y que prometía extender sus beneficios a los vecinos, integrados laboralmente al proyecto, en un ambiente de convivencia y creatividad. La narrativa de Fugaz prometía eso y la realidad parecía confirmarlo. El arte era la piedra de toque del exitoso proyecto (Fugaz | Arte de Convivir s/f).

En 2017, sin embargo, surgieron datos disonantes. El dueño de Fugaz fue involucrado en el escándalo de corrupción de la empresa brasileña Odebrecht junto con el gobernador regional del Callao de aquel momento. El antropólogo Mijail Mitrovic caracterizó entonces el proyecto como un caso de gentrificación (2017), un tema sobre el que el periódico inglés The Guardian, en un artículo firmado por Oliver Wainwright (2016), ya había alertado meses antes. El dueño de Fugaz habría adquirido y restaurado la Casa Ronald y dado forma al proyecto con fines de especulación 


\section{FIGURA 5}

Mural de Decertor. Fotografía: Gabriela Vásquez.

\section{FIGURA 6}

Obra site specific de los hermanos José Luis y José Carlos Martinat. Al fondo, el edificio Ronald. Foto: Talía Echecopar, Stylish life.
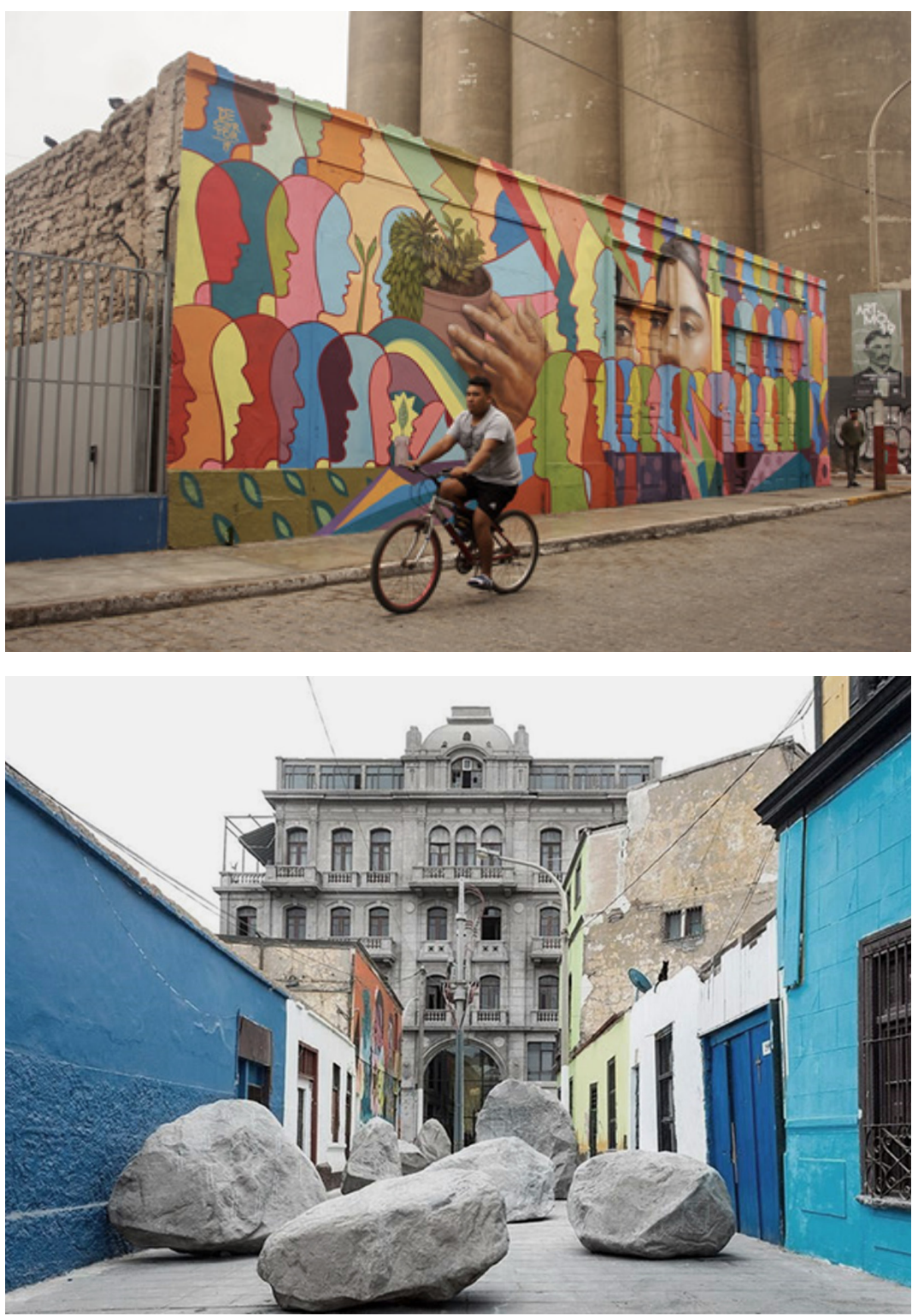
inmobiliaria, presuntamente como complemento de una operación de intermediación en sobornos destinados a favorecer la ejecución de la obra vial de la Costa Verde Callao por Odebrecht (Cavello Limas 2017).

A estas denuncias le siguieron el alejamiento del proyecto de varios artistas y empresarios, y serios cuestionamientos a su accionar y a la escasa integración alcanzada en términos de convivencia con sus vecinos originarios. Se ha dicho que se intervino una zona intangible y se pintaron casas de valor patrimonial, vulnerando su identidad histórica. ${ }^{6}$ Que no necesariamente «más arte» significa «más comunidad», y que en el objetivo de construir comunidad a veces se pierde de vista a costa de qué se consigue. ${ }^{7}$ Se han observado inconsistencias en la construcción de la experiencia de renovación urbana e indicado que el territorio de Fugaz aparece demarcado por la ornamentación con banderines y azulejos de las calles, cuya presencia/ausencia señala el límite excluyente entre Fugaz y su entorno. Que la transformación del espacio se ha dado a través del consumo y su apropiación por los visitantes, sus verdaderos usuarios; y que la experiencia urbana de estos se sostiene sobre una narrativa que exalta la confluencia del arte con la marginalidad. ${ }^{8}$ Finalmente, se ha cuestionado el modelo de intervención de Fugaz en la zona, señalando que reproduce el modelo neoliberal, y tiene como consecuencia desarticular el descontento social, la solidaridad de clase y toda forma de confrontar el capitalismo. ${ }^{9}$

Lo cierto es que, como espacio público, si bien Fugaz ha mejorado el barrio en términos estéticos y arquitectónicos, Monumental Callao no ha generado convivencia real entre los vecinos de la zona; por el contrario, es un enclave económico en medio del Callao que está perpetuando viejos vicios. A cada cuestionamiento le ha seguido una nueva estrategia de forzada permanencia y liderazgo de Fugaz. Cuando la integración vecinal fue cuestionada, los directivos del proyecto invitaron a una lideresa comunal, quien ahora decide quiénes obtienen un contrato de trabajo en la zona y quiénes no (Eslava Jaime 2019: 66-67). Ningún puesto laboral de importancia es ocupado por un vecino original. Mientras tanto, nuevos grafiteros están interviniendo los muros, superponiendo sus graffiti sobre los de otros artistas urbanos, buscando solo un lugar donde expresarse, con mensajes ambivalentes, algunos lindando con la apología del crimen, sin meditar sobre el valor y el significado del arte en el espacio público. Por otro lado, las viviendas en su mayoría siguen siendo solo fachadas, coloridos contenedores del abandono y la pobreza. Todo proyecto de intervención urbana debería ser sometido a debate y deliberación, recordando siempre que el espacio público es un espacio político de pugna entre el poder y el contrapoder (Martucelli 2007: 66); que el arte tiene la capacidad de construir visiones de otros mundos posibles; y el artista, la de elegir entre ser funcional

6 Para más información, véase Castillo Dávila 2017.

7 Véase Mitrovic 2017.

9 Véase Eslava Jaime 2019 a las estructuras de dominación o ser incómodo al sistema.

\section{Malecón de Miraflores, entre el canon y la dinámica social}

El malecón de Miraflores está ubicado en el acantilado que bordea el circuito de playas de la Costa Verde, sobre la franja del litoral correspondiente 


\section{FIGURA 7}

Plano de ubicación de las esculturas: 1. Pedro Paulet. 2. Ají peruano. 3. Hacia la gloria. 4. Monumento a Alfredo Salazar. 5. Oso Paddington 6. Totem. 7. San Marcelino Champagnat. 8. Virgen María. 9. Amarre 10. Intihuatana. 11. Cupido. 12. El Beso. 13. Monumento a Antonio Raimondi. 14. Carlos de los Heros. 15. Entre el Tiempo. Elaboración propia sobre una imagen de Google Earth.

10 En el parque Domodossola el busto de Pedro Paulet, de autor no identificado, y la escultura contemporánea al Ají peruano de Edi Mérida. En el parque Salazar, dos obras de Lajos D'Ebneth, vanguardista húngaro de la Bauhaus: la escultura Hacia la gloria y el monumento a Alfredo Salazar Southwel; y la estatua de Oso Paddington, obsequio de la embajada británica al distrito de Miraflores. En el Parque Letonia, la escultura contemporánea Tótem, de Aldo Chaparro. En el parque Champagnat, una escultura figurativa que representa a la Virgen María y el busto de San Marcelino Champagnat. Junto al puente Villena, en el malecón 28 de Julio, la escultura contemporánea Amarre, de Sonia Prager.

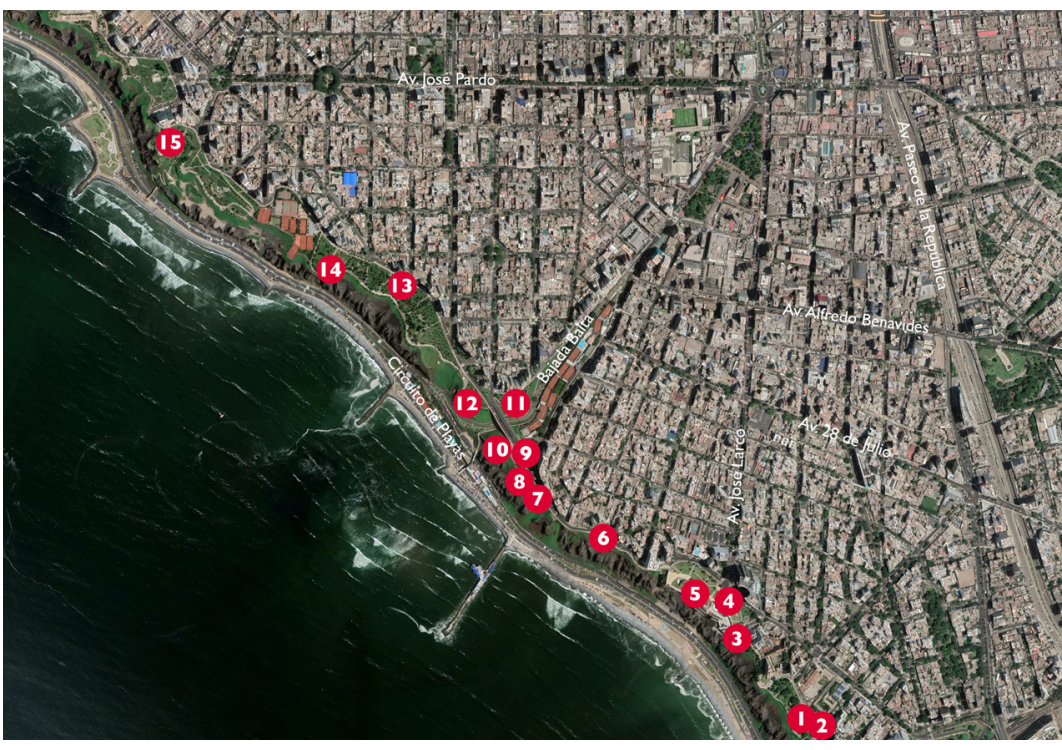

al distrito, desde la bajada de Armendáriz hasta la bajada San Martín, pasando por la bajada Balta. Comprende los malecones Armendáriz, De la Reserva, 28 de Julio, Balta, Cisneros y De la Marina, y a lo largo de sus cinco kilómetros integra una docena de parques de acceso libre; en conjunto, un gran espacio público lineal y continuo con vista al océano Pacífico, en el que se han privilegiado las áreas verdes y se le ha dado cabida al arte con obras relativamente recientes.

A lo largo de estos parques se encuentran quince esculturas, entre obras de corte contemporáneo, bustos y monumentos. ${ }^{10}$

El conjunto de estas obras configura una suerte de circuito de arte que hoy se encuentra establecido y es promocionado como tal por la Municipalidad de Miraflores. Sin embargo, la instalación de algunas obras contemporáneas fue hecha con controversia, pese a ser de autoría de reconocidos artistas plásticos. Dos de estas esculturas, en particular, generaron furiosos ataques y una encendida polémica entre defensores y detractores: El beso, de Víctor Delfín, y Entre el tiempo, de José Tola. ${ }^{11}$ La primera fue considerada por sus detractores como grotesca y ajena a la identidad estética miraflorina. La segunda fue llamada monstruosa y kitsch. Lo interesante de esta polémica es el discurso que está detrás y el poder del arte para cuestionar la mentalidad de las personas.

En el caso de El beso, la crítica tenía un trasfondo de discriminación racial: la escultura difiere del estereotipo miraflorino y muestra una pareja mestiza. Al respecto, el periodista Roberto Ochoa narra lo siguiente: «No faltaron quienes resaltaron que [...] su estética "no era miraflorina". La mujer era demasiado gruesa, demasiado rechoncha, demasiado chola. De ahí que recomendaron sacarla de Miraflores para instalarla "en algún otro parque de Lima"» (2013: s. n. p.). ${ }^{12}$ La crítica a Entre el tiempo —-también llamada Silencio—, más que con su estética, tuvo que ver con el distanciamiento entre el autor y el público, patentizada el día de su presentación 
En el parque Mariano Necochea, Intihuatana, del escultor contemporáneo Fernando de Szyszlo. En el parque Juan Carossio, la escultura contemporánea Cupido, de Marcelo Wong. En el Parque del Amor, en el malecón Cisneros, El beso, escultura contemporánea de Víctor Delfín. En el parque Raimondi, el busto del marino Carlos de los Heros y el monumento a Antonio Raimondi. Finalmente, en el parque Itzhak Rabin o Del Libro, la escultura contemporánea Entre el tiempo, de José Tola.Para más información, véase Castillo Dávila 2017.

11 Para informarse más sobre esta polémica, véanse Ochoa 2013 y Niño de Guzmán 2013. en el incoherente discurso de Tola, considerado una burla intencional (RPP Noticias 2013). En ambos casos, las críticas evidencian la resistencia a un arte impuesto desde la institucionalidad, sin consulta con los vecinos; arte que, sin embargo, ha pasado del debate a la aceptación, la comprensión de la obra, la identificación con ella y la democratización del espacio público.

El beso ha dado lugar a que el parque donde se ubica se convierta en un lugar icónico, un locus metropolitano frecuentado por grupos de amigos, parejas de enamorados y novios, hoy llamado, por eso, Parque del Amor, un espacio urbano que Víctor Delfín define con orgullo como «un espacio para la gente, un espacio para el gran público» (Municipalidad de Miraflores 2016). Entre el tiempo, una colorida escultura bifronte, es conocida también como Sol y Luna (Ochoa 2013). Ambas piezas forman parte de un espacio público que, trascendiendo su carácter distrital, se ha constituido en un nodo turístico y peatonal de importancia metropolitana (GDUMA 2016: 149).

Cabe mencionar aquí el concepto de «activación» que menciona Elio Martucelli (2007: 60). El parque, al igual que la calle, es de todos y es de nadie, y permite el juego de poder, las fisuras, las provocaciones y respuestas. El espacio público no es solo un lugar de encuentro; es también un espacio político en pugna. El arte activa y resignifica un lugar, y en el caso de Miraflores activó espacios — que podrían haber sido solo de contemplación del paisaje- como lugares de debate y confrontación, para finalmente derivar en negociación, acuerdo y convivencia por efectos de la propia dinámica social.

Parafraseando al urbanista holandés Joe Coenen, puede decirse que contribuyó a esto la reestructuración de esta área neurálgica, de la mano de planes integradores de conformación de espacios públicos reconocibles como tales, no solo en términos formales, sino también de relaciones, significados y movilidades (1999: 32-33). Miraflores inició la transformación de la Costa Verde en la década de 1980 y tiene un plan de desarrollo integral para el distrito diseñado hasta el año 2026, que prevé articular los espacios públicos que se asoman al océano con el entorno edificado, las áreas verdes, los circuitos viales, las playas y terrenos posplaya y los planes de desarrollo cultural y económico (GDUMA 2016).

\section{Reflexiones finales}

El tema de las interacciones entre arte y espacio público es complejo y tiene aristas que involucran aspectos económicos, políticos, ideológicos y sociológicos relacionados con las profundas transformaciones experimentadas por la ciudad en los últimos tiempos. Su análisis amerita una profunda reflexión crítica que excede los límites de este artículo, pero a la cual es necesario apuntar.

El encuentro entre el arte y el espacio público exige, ahora, una mirada contemporánea que articule su dimensión vecinal cívica y política a una visión pragmática e integradora de la ciudad y sus planes de desarrollo. La administración local juega un papel decisivo, pero no más 


\section{FIGURA 8}

El beso, de Víctor Delfín, en el Parque del Amor. Fotografía: Alvaro Sánchez Casas.

\section{FIGURA 9}

Entre el tiempo, de José Tola, en el Parque del Libro. Fotografía: Alvaro Sánchez Casas.
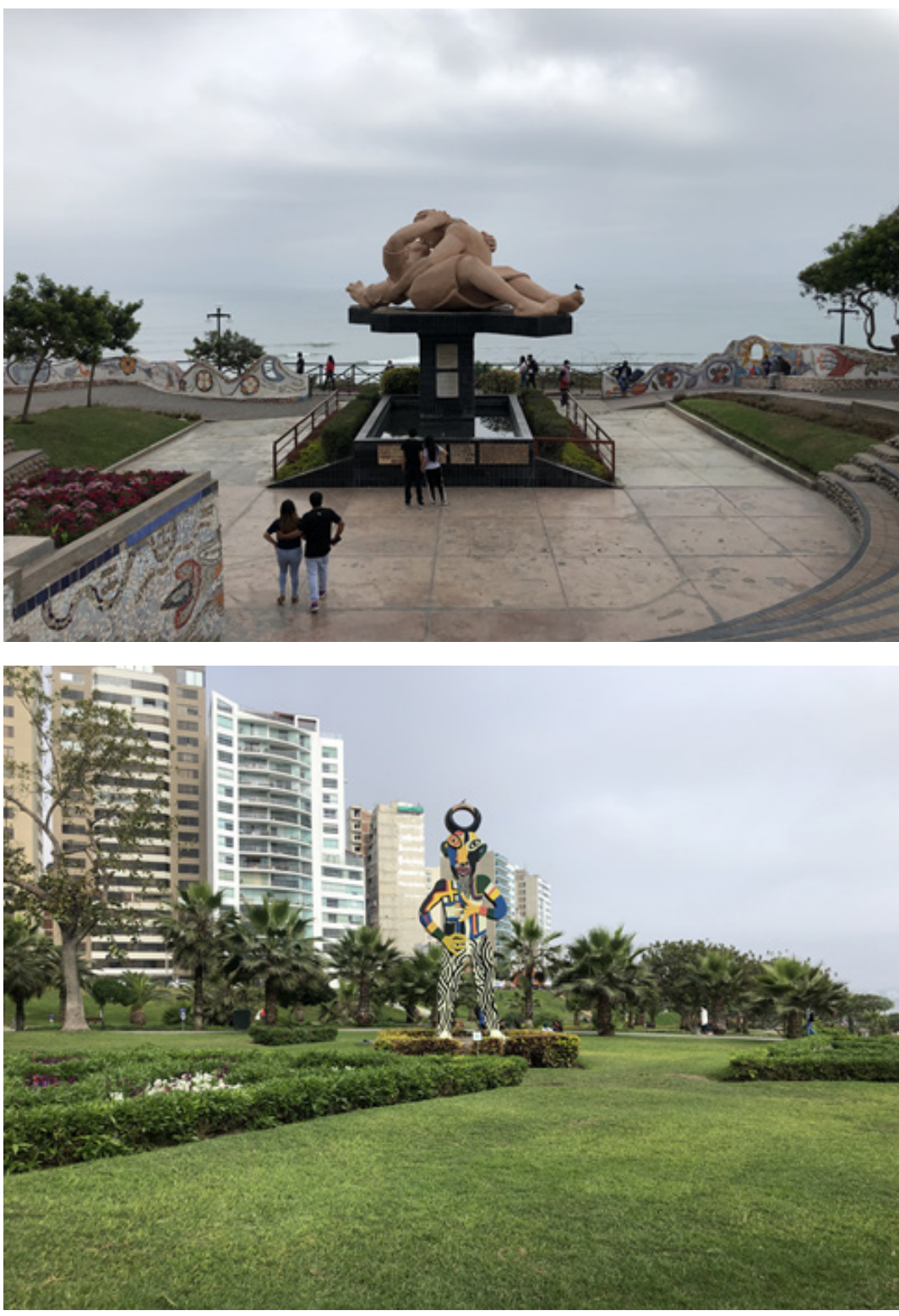
importante que el de las organizaciones vecinales, los colectivos artísticos y culturales, los artistas, arquitectos y, en general, los usuarios del espacio público. La ciudad es del interés de todos y su reestructuración requiere la generación de sinergias y de una dependencia recíproca entre todos sus agentes y actores, especialmente entre las instituciones públicas y privadas que intervienen en su planificación, organización y cuidado.

Como se ha visto, Lima no ha sido inmune a la privatización de sus espacios públicos y a la utilización descriteriada o indebida del arte en ellos. Lograr espacios públicos coherentes y significantes, donde lo artístico no sea un simple pretexto o un accesorio, implica ver al arte como un vehículo de democratización y transformación de la ciudad, siempre con vistas a la apropiación de esta por sus habitantes y a la mejora de su calidad de vida en tanto miembros de una colectividad.

Implica, asimismo, pensar la ciudad; reflexionar sobre las maneras de habitarla hoy, en esta época de globalización, de los nuevos modos de vida fuertemente influidos por la tecnología y la comunicación audiovisual, en medio de complejas infraestructuras urbanas, complicadas redes viarias multimodales y espacios periurbanos en crecimiento continuo. Interrogarse sobre la ciudad es pensar en el significado de sus espacios públicos como lugares de encuentro, negociación y transgresión de sus ciudadanos, pero también de creación, re-creación y transformación. Espacios para vivir con arte y creatividad, entendidos no solo como producción artística, sino también como dinámicas de intercambio y re-significación cultural.

En este contexto, proyectar la ciudad con arte puede comprender vivirla de manera lúdica, admirando los signos de su presencia, nutriéndonos de cada momento presente, guardando en la memoria sus historias, colores y rincones secretos. Si realizáramos una deriva por Lima, como la propuso Guy Debord, esta podría guiarnos a descubrir sus latidos vitales en los colores brillantes de la escultura de José Tola en el malecón de Miraflores, en el vibrante rojo de la escultura de Marcelo Wong en el Boulevard de la Cultura de Magdalena del Mar o, tal vez, en la inquietante frialdad de las rocas de los hermanos Martinat en Monumental Callao. El arte nutre la ciudad de vida, puede transformar un recorrido cotidiano en una experiencia irrepetible, a veces provocadora, en ocasiones sublime.

\title{
Bibliografía citada
}

\author{
ANDINA \\ 2012 «Instalan Museo de Arte Público en avenida Javier Prado Oeste». Andina, Agencia Peruana de \\ Noticias. Lima, 18 de noviembre. Consulta: 19 de abril de 2020. https://andina.pe/agencia/noti- \\ cia-instalan-museo-arte-publico-avenida-javier-prado-oeste-436411.aspx \\ ARTISHOCK \\ 2016 «Proyecto Fugaz convierte a una zona de Perú en destino para el arte». Artishock Revista de \\ Arte Contemporáneo. Santiago de Chile, 1 de agosto. Consulta: 1 de mayo de 2020. https:// \\ artishockrevista.com/2016/01/08/proyecto-fugaz-convierte-una-zona-peru-destino-arte/ \\ BRAVO, Luisa \\ 2013 «Open Spaces, Public Spaces, Publics, Open-minded Places». Project: Past Present and Future \\ of Public Space. Research Group. Consulta: 8 de junio de 2020. https://www.researchgate.net/ \\ publication/236866831_Open_Spaces_Public_Spaces_Publics_Open-minded_Places
}


BOURRIAUD, Nicolas

2008 Estética relacional. Segunda edición. Buenos Aires: Adriana Hidalgo editora.

CASTILLO DÁVILA, Bryan

2017 «Cuando el arte vulnera la identidad de un lugar». En Larana, 15 de abril. Consulta: 20 de mayo de 2020. https://www.larana.pe/2017/04/cuando-el-arte-vulnera-la-identidad-de.html

CAVELLO LIMAS, Edwin

2017 «Odebrecht, Gil Shavit y Callao Monumental». En Lima Gris, 3 de abril. Consulta: 24 de mayo de COENEN, Joe 2020. https://limagris.com/odebrecht-gil-shavit-callao-monumental/

1999 «Reflexiones y experiencias sobre el tema del espacio público». En JUNTA DE ANDALUCíA. La arquitectura del espacio público. Formas del pasado formas del presente, pp. 32-36. Sevilla: Consejería de Obras Públicas y Transportes de la Junta de Andalucía. Consulta: 4 de mayo de 2020. https://ws147.juntadeandalucia.es/obraspublicasyvivienda/publicaciones/01 ARQUITECTURA Y VIVIENDA/la_arquitectura_del_espacio_publico/la_arquitectura_del_espacio_publico.pdf

ECHECOPAR, Talía

s/f «Arte en el Callao: Proyecto Fugaz». En A stylish life. Consulta: 20 de mayo de 2020. http://asl. pe/inspiracion/proyecto-fugaz/

ESLAVA JAIME, Paula

2019 Monumental Callao: institucionalidad artística contemporánea y cultura política neoliberal desde una lectura crítica de la ideología. Tesis de maestría en Estudios Culturales, Pontificia Universidad Católica del Perú.

FUGAZ | Arte de Convivir

s/f Monumental Callao. Consulta: 25 de mayo de 2020. https://www.monumentalcallao.com/

GDUMA

2016 Plan Urbano Distrital de Miraflores 2016-2026. Lima: Gerencia de Desarrollo Urbano y Medio Ambiente de la Municipalidad de Miraflores GDUMA. Consulta: 1 de junio de 2020. http://www. miraflores.gob.pe/Gestorw3b/files/pdf/10299-25442-capitulosiyii.pdf

GÓMEZ AGUILERA, Fernando

2004 «Arte, ciudadanía y espacio público».On the W@terfront, n. ${ }^{\circ} 5$, marzo. Consulta: 5 de mayo de 2020. https://revistes.ub.edu/index.php/waterfront/article/view/18957/21417

GROYS, Boris

2011 «Introduction. Global Conceptualism Revisited». e-fluxs Journal, n. ${ }^{\circ} 29$. Consulta: 2 de mayo de 2020. https://www.e-flux.com/journal/29/68059/introduction-global-conceptualism-revisited/

IMP, INSTITUTO METROPOLITANO DE PLANIFICACIÓN

2010 Plano de Zonificación Urbana de Lima Metropolitana Magdalena del Mar, Áreas de Tratamiento Normativo 2 y 3 [mapa]. Lima: Municipalidad Metropolitana de Lima. Consulta: 6 de junio de 2020. https://www.imp.gob.pe/images/Planos\%20de\%20Zonificacion/1\%20Magdalena.pdf

JANUCHTA-SZOSTAK, Anna

2010 «The Role of Public Visual Art in Urban Space Recognition». En PERUSICH, Karl (editor), Cognitive Maps, pp. 75-100. Croacia: In Tech. Consulta: 1 de junio de 2020. https://www.intechopen.com/ LUDEÑA, Wiley books/cognitive-maps/the-role-of-public-visual-art-in-urban-space-recognition

2013 «Espacios públicos, arte urbano y diseño. La otra ciudad peruana». En HAMANN, Johanna (editora), Lima: espacio público, arte y ciudad, pp. 155-188. Lima: Pontificia Universidad Católica de Perú. Consulta: 18 de abril de 2020. http://facultad.pucp.edu.pe/arte/files/2016/07/Libro-Lima_Espacio-P\%C3\%BAblico-Arte-y-Ciudad.pdf

MARTUCCELLI, Elio

2007 «Poder, deber y querer. Arte urbano. Intervención en espacios públicos». Arquitextos, Revista de la Facultad de Arquitectura y Urbanismo de la Universidad Ricardo Palma, n. ${ }^{\circ} 22$, pp. 59-69.

MENDOZA BAZÁN, Brenda

2019 «Un acercamiento etnográfico a la construcción de la experiencia urbana de los visitantes del Proyecto Fugaz en el área monumental del Callao». Ponto Urbe, Revista do Núcleo de Antropologia Urbana da USP, n. ${ }^{\circ}$ 24. Sao Paulo. Consulta: 2 de mayo de 2020. https://journals.openedition. org/pontourbe/6586

MITRACHE, Georgică

2012 «Architecture, art, public space». Procedia. Social and Behavioral Sciences, n. ${ }^{\circ}$ 51, Bucarest, pp. 562-566. Consulta: 18 de abril de 2020. https://core.ac.uk/download/pdf/82070556.pdf

MITROVIC, Mijail

2017 «Transparencia y opacidad en Monumental Callao». En Disonancia. Portal de debate y crítica social. Consulta: 20 de mayo de 2020. https://disonancia.pe/2017/04/24/transparencia-y-opacidad-en-monumentalcallao/

MUNICIPALIDAD DE MIRAFLORES

2016 El beso de Víctor Delfín [videograbación]. Lima: Mira TV. Consulta: 30 de abril de 2020. https:// www.youtube.com/watch?v=fnDAadgbHnc\&feature=youtu. be\&fbclid=IwAR39J8PWpc-QiJXwDSrxGaVRaY7ij-jqsEjSOMr_sn7mmeKykKFQktRcS40 
MUSEO DE ARTE DE LIMA

2012 «Proyectos artísticos en el Centro Histórico de Lima». En MALI. Consulta: 10 de junio de 2020. http://www.mali.pe/not_detalle.php?id=74\&p=ant\&anio=2012

NIÑO DE GUZMÁN, Guillermo

2013 «El monstruo del malecón Cisneros». Perú 21, 1 de diciembre. Consulta: 24 de mayo de 2020. https://peru21.pe/opinion/monstruo-malecon-cisneros-134693-noticia/

OCHOA B., Roberto

2013 «Un museo al aire libre en Miraflores». La República. Lima, 30 de noviembre. Consulta: 15 de abril de 2020. https://larepublica.pe/archivo/755353-un-museo-al-aire-libre-en-miraflores/ RPP NOTICIAS

2013 «Artista Tola brinda irreverente discurso en presentación en Miraflores». RPP Noticias. Consulta: 20 de mayo de 2020. http://rpp.pe/lima/actualidad/artista-tola-brinda-irreverente-discurso-en-presentacion-en-miraflores-noticia-649183

TOKESHI, Juan

2013 «Arte y espacio público. Una ventana abierta a la cultura popular». En HAMANN, Johanna (editora), Lima: espacio público, arte y ciudad, pp. 117-136. Lima: Pontificia Universidad Católica del Perú. Consulta: 16 de abril de 2020. http://facultad.pucp.edu.pe/arte/files/2016/07/Libro-Lima_Espacio-P\%C3\%BAblico-Arte-y-Ciudad.pdf

URDA PEÑA, Lucila

2015 El espacio público como marco de expresión artística. Tesis de doctorado en Urbanística y Ordenación del Territorio, Universidad Politécnica de Madrid, Escuela Técnica Superior de Arquitectura. Consulta: 23 de abril de 2020. http://oa.upm.es/36260/1/LUCILA_URDA_PENA_01.pdf WAINWRIGHT, Oliver

2016 «We are building our way to hell': tales of gentrification around the world». The Guardian, Londres, 5 de octubre. Consulta: 16 de junio de 2020. https://www.theguardian.com/cities/2016/ oct/05/building-way-to-hell-readers-tales-gentrification-around-world 